International Journal of Engineering \& Technology, $7(2.29)(2018) 815-820$
International Journal of Engineering \& Technology
SPC
Website: www.sciencepubco.com/index.php/IJET
Research paper

\title{
Performance of Soil Water Content Using Ground Penetrat- ing Radar with Different Antenna Frequencies
}

\author{
Nurul Izzati Abd Karim ${ }^{1 *}$, Samira Albati Kamaruddin², Rozaimi Che Hasan ${ }^{3}$ \\ ${ }^{1,2,3}$ Engineering Department, UTM Razak School of Engineering and Advanced Technology, \\ Universiti Teknologi Malaysia, Jalan Sultan Yahya Petra, Kuala Lumpur, Malaysia. \\ *Corresponding Author E-Mail: Nurulizzati7790@Gmail.Com
}

\begin{abstract}
Accurate measurements of Soil Water Content (SWC) with applicable and relevant support are essential in many fields of earth and soil engineering research. Ground Penetrating Radar (GPR) is a geophysical tool that measures and provides accurate results for determination of the SWC. To prove the accuracy of SWC measurement using GPR, a field survey was performed in peat soil. This paper presents a fieldwork survey with the aim of assessing the SWC measurement using GPR. The survey work was conducted at Johor Bharu using different antenna frequencies ( 250 and $700 \mathrm{MHz}$ ). Five profiles, which is $5 \mathrm{~m}$ by $5 \mathrm{~m}$ in length, were scanned along an eastwest direction with a common offset at an equal spacing of $1 \mathrm{~m}$. To measure the SWC using GPR, the researchers used the velocity from the GPR's signal from the receiving antenna to the soil. Statistical analysis was carried out based on the dielectric permittivity and SWC. Schaap's equation and Roth's equation were used to distinguish the relative dielectric permittivity of the soil to SWC. The results of this study show the linear function, $\theta_{2}$ for the measured SWC. The validation graph shows that at a frequency of $250 \mathrm{MHz}$, the depth of penetration was greater compared to the frequency of $750 \mathrm{MHz}$. These results, suggest that a higher frequency will give higher resolution but lower depth penetration.
\end{abstract}

Keywords: Soil Water Content; Petrophysical Relationship; Ground Penetrating Radar; Antenna Frequencies; Geophysical Tool; Dielectric Permittivity.

\section{Introduction}

Soil water (moisture) content is generally defined as the amount of water contained in the unsaturated soil zone (1). It is one of the parameters and vital factors in the quality control of peat soil, especially in agriculture and climate studies. Without water, plants cannot absorb the nutrients in the soil, which causes the quality of the plants to decrease. In addition, often less attention is paid to peat soil, for which the risk and impact increase as the water content is diminishing and becoming a limited and widely exploited resource that is unequally distributed in space and time(2). Therefore, knowledge about the water content in peat soil is needed. Being able to accurately determine the Soil Water Content (SWC) is important for the characterization of peat soil and has boosted the development of SWC methods. These methods can be categorized as either direct or indirect. Drilling with sampling is one of the direct methods for the estimation of the SWC; however, it is inefficient, destructive and discontinuous. Hence, other methods are used to determine SWC, such as the gravimetric method, which is considered to be the standard/approved method. Nevertheless, the method is time-consuming and destructive. Several researchers (3-9) have claimed that some of the SWC estimation methods use physical properties, such as electrical resistance, temperature, capacitance, dielectric permittivity or spectrometry. Even though the methods are efficient, they are relatively expensive, which limits their widespread application. The use of in-direct methods was introduced in the past as the conventional methods are invasive, time-consuming, labor-intensive and destructive(10). Table 1.1 shows a comparison of the direct methods (Gravimetric, Neutron probe, TDR,
Capacitance, Tensiometer) and in-direct methods (Gamma ray, Remote sensing, Capacitance sensor, Pressure plate and GPR) which have been categorized into approach/tools, accuracy and measured parameters. Because of the limitations of the direct methods, the electromagnetic (EM) approach has been tested and approved in soil science and hydrogeophysics; such approaches include Ground Penetrating Radar (GPR), (11-14) and Electromagnetic Induction (EMI) (15-17). Besides, Direct Current (DC) method $(18,19)$ is no exception for SWC estimation. GPR is a strategic way to estimate the SWC, as it is a non-invasive tool that produces high-resolution extended profiling of an area and can yield much data and information compared to the conventional method for SWC estimation in peat soil.

Table 1.1: Comparison of Direct Methods and Indirect Methods

\begin{tabular}{|l|l|l|}
\hline Approach/Tools & Accuracy & Measured parameter \\
\hline Gravimetric & High & Mass $\theta$ \\
\hline Neutron Probe & High & Volumetric $\theta$ \\
\hline $\begin{array}{l}\text { Time Domain Reflectometry } \\
\text { (TDR) }\end{array}$ & High & Volumetric $\theta$ \\
\hline Capacitance & & Volumetric $\theta$ \\
\hline Tensiometer & High & Soil Water Potential \\
\hline Gamma Ray & Low & Volumetric $\theta$ \\
\hline Remote Sensing & Low & Soil Surface Moisture \\
\hline Capacitance Sensor & High & Volumetric $\theta$ \\
\hline Pressure Plate & Low & Soil Water Potential \\
\hline GPR & High & Volumetric $\theta$ \\
\hline
\end{tabular}

Note: $\theta$ is water content 
Knowledge of GPR is an important practical aspect to undertake the estimation of the SWC. Understanding how the energy is transmitted and received by the particular GPR antenna can be useful and facilitate improved signal processing. This geophysical tool uses radar pulses to image the subsurface. Unlike other conventional tools (20) for SWC estimation, (21) defined that, GPR is a non- destructive instrument that uses electromagnetic (EM) energy where the signals is detect and reflect from the subsurface. In addition, due to the good penetration (22) and resolution(20), GPR can be used for a variety of applications, such as agriculture, engineering, investigating archaeological sites, and hydrological purposes, especially when related to peat soil. In scanning peat soils, GPR plays an important role in estimating the SWC as it is the survey device for the imaging and characterizing of the internal structure of peat soil. Although peat soil has very complex (23) and unpredictable physical properties, GPR's potential for detecting and estimating the SWC for peat soil is proven in the literature(24). GPR is a high-resolution geophysical tool that consists of a transmitter, receiver and antenna frequency. Fig 1 shows the components of the GPR. The GPR reliability and capability is strongly depend on the central frequency. It has been previously noted that, as the frequency of GPR antenna increases, the image (resolution) becomes sharper. However, conversely, the penetration of the signal diminishes. Hence, the choice of the antenna frequency for a GPR survey is a key factor in terms of its performance for the detection and estimation of the subsurface features.

\subsection{GPR Principles}

Ground Penetrating Radar (GPR) is a geophysical method that uses electromagnetic wave (EM) energy at frequencies of $50-1500$ $\mathrm{MHz}$ for subsurface detection (25). It consists of an impulse generator that sends a signal of fixed voltage and frequency spectrum to a transmitting antenna. Figure 1 shows the components of a GPR system. The antenna is a very important part as it is from here that the radar signal is transmitted and received. The parts of GPR antenna consist of transmitter and receiver. The transmitter functions for signal propagation while receiver functions for signal detection. Timing units is the heart of GPR that synchronizing the transmitter and receiver. The component that controls the overall operation is the control unit that relays the receiver data to the data storage and display unit. A portion of energy is lost to the air when the antenna of the GPR directs EM energy into the subsurface. As the EM waves propagate through the air, they can encounter the subsurface with different dielectric permittivities, which causes part of the signal to be reflected to the receiver. (26) proved that, using the lower frequency of GPR antenna (e.g., $100 \mathrm{MHz}$ ) was more effective, which has a longer wavelength but lower resolution, and useful for locating the water table depth and identifying small features up to a depth of $5 \mathrm{~m}$, but that it becomes less effective for depths up to $20 \mathrm{~m}$. The amplitude becomes decreases when the ratio between the thickness of the transition zone and the wavelength is greater than 0.3 and the water table reflection cannot be detected $(27,28)$.

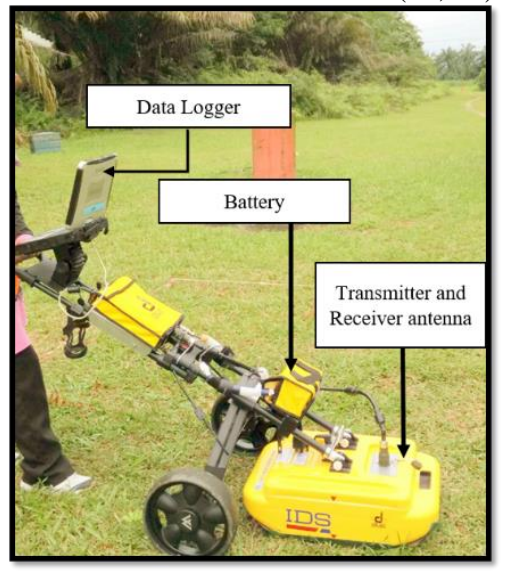

Fig. 1: Components of GPR
The GPR system is based on the transmission and reflection of the EM waves in the soil (29). The GPR uses the seismic reflection method, which provides high and better resolution because it emits EM energy (30). The reliability of the GPR system strongly depends on the antenna frequencies. Some of the energy signal is dispersed and absorbed by the soil when the antenna transmits the EM energy into the ground, and some is reflected back to the antenna when the radiated energy collides with an interface. (31) claimed that the antenna of the GPR is the significant factor in survey measurements as it determines the resolution and depth of penetration. A high frequency leads to high resolution and high attenuation, but low depth penetration compared to a low frequency. The selection of the antenna frequency is determined by the desired resolution and the achievable depth penetration. (32) mentioned that it is better to trade the resolution for depth, as high resolution can hinder the detection of the target. Table 1.2 shows the guideline for a few of GPR center frequency values. The guideline can be used to determine the best frequency for the measurement

Meanwhile, the computed parameters are time travel and amplitude of the reflected EM energy. These parameters depend on the electrical and EM energy, such as permittivity, the conductivity of the material, and the magnetic permeability of the medium (32). The EM waves and dielectric permittivity are influenced by the SWC.

Table 1.2: Guideline for GPR Centre Frequency Values

\begin{tabular}{|c|c|}
\hline Depth (m) & Centre Frequency (MHz) \\
\hline 1.0 & 500 \\
\hline 5.0 & 100 \\
\hline 10.0 & 50 \\
\hline 50.0 & 10 \\
\hline
\end{tabular}

\section{Materials and Methods}

\subsection{Experimental Setup}

This study was conducted on the Universiti Teknologi Malaysia (UTM) campus at Johor Bharu, which is covered with an oil palm plantation. The area is covered with peat soil. The survey was done using longitudinal and transversal movement to find the correlation of the signal. The length profiles were scanned in an east-west direction with a common offset at an equal spacing of $1 \mathrm{~m}$. A $5.0 \mathrm{~m}$ by $5.0 \mathrm{~m}$ survey grid, perpendicular to the direction was set up in the site area (Figure 2). The GPR survey lines were installed and used for scanning along the fixed ropes. The fixed ropes were installed and set up temporarily at the starting and ending points of the marked survey lines to facilitate accurate repeatability of the survey area. The interval between the lines was $1.0 \mathrm{~m}$. A fixed rope was used to guide the GPR during scanning, to ensure the repeatability of the locations and intervals of the survey lines. Figure 3 shows the GPR fieldwork survey of the study area. The fieldwork survey involved scanning over the oil palm plantation area. The scanning was conducted using the GPR Detector Duo, radar acquisition unit known as IDS DAD Fast Wave GPR with a dual frequency $(250 \mathrm{MHz}$ and $700 \mathrm{MHz})$. This work is an experimental research designed to estimate the soil water content in peat soil. The study area was surveyed before the fieldwork began. The lines were marked with a fixed rope, and the calibration of the GPR scanning was done before the actual scanning began. The scanning began in an east-west direction to obtain the signal repeatability of the survey area. 


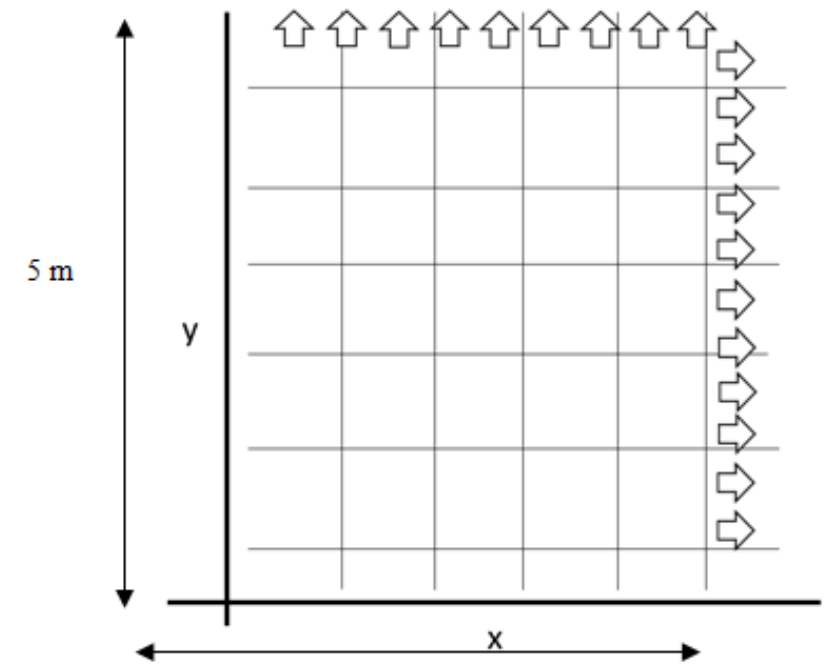

Fig. 2: Schematic diagram for survey measurements
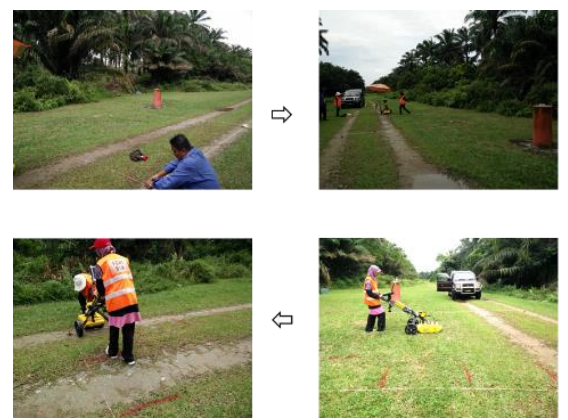

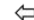

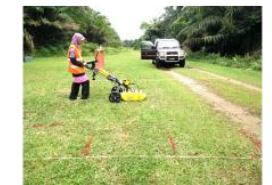

Fig. 3: GPR Fieldwork Survey

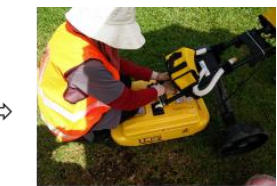

ת

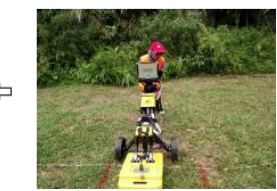

\subsection{GPR Instrument and Survey}

The instrument used was a Ground Penetrating Radar (GPR) with dual frequency (IDS Detector Duo with 250 and $750 \mathrm{MHz}$ ), and the test beds were filled with peat soil. The GPR was used to undertake the survey to extract the parameters of the soil in terms of the SWC and dielectric permittivity. The GPR scanning displayed the deep and shallow channels on the screen of the tough book. Researchers have claimed that the higher the frequency, lead to improve the resolution, but less depth penetration. The figure shows the IDS Detector Duo. Five profiles, each $1 \mathrm{~m}$ in length, were scanned along the east-west direction with a common offset at an equal spacing of $1 \mathrm{~m}$. The velocity can be computed from the travel time to the target at a known depth. The computed velocity can then be used to estimate the dielectric permittivity using a mathematical formula for high radar frequencies in soils that have low electrical conductivity(33).

$\varepsilon=\left(\frac{c}{w}\right)^{2}$

where $\varepsilon$ is the dielectric permittivity and $c$ is the airwave velocity $\left(3 \times 10^{8} \mathrm{~m} / \mathrm{s}\right)$. However, the velocity can be frequency dependent, especially at lower frequencies and in complicated soils like peat. Hence, the empirical equation given in (2.1) cannot be applied. For low frequencies, the dielectric permittivity of unsaturated soil is water content dependent (34), albeit other factors, such as the temperature and soil surface area, may contribute to the GPR results. The water content highly influences the dielectric permittivity of the soil, and, hence, variations in the amount of water in the soil change the soil dielectric constant. Accordingly, the petrophysical model can be used by either using the existing equations (reference) or developing a model.

\subsection{Petrophysical Relationships}

The GPR used the transmission and reflection of frequency $(1 \mathrm{MHz}$ $-1 \mathrm{GHz}$ ) of the electromagnetic waves within the subsurface. This non-invasive tool measures the travel time from the transmitter to the receiver antenna through the topmost layer of the soil, which correlates to the dielectric permittivity of the soil water content measurement. However, obtaining an estimate of the water content of the soil requires an appropriate petrophysical relationship between the dielectric permittivity and the water content. Researchers have discussed in detail in many previous studies the issues concerning the instruments, large-scale, and small-scale. Some methods, such as the capacitance probe, use a different approach; after measuring the capacitance, it is then converted to dielectric permittivity. From a previous study, it can be seen that the information concerning the dielectric permittivity plays an important role as it can be computed to estimate the water content. Dielectric permittivity is the most common electrical property used to measure the SWC. Several empirical equations have been proposed by researchers $(35,36)$ to estimate the water content in soil, such as the Topp's equation(27), Richard's equation, Genuchten parameters(28) and Roth's equation. However, only a few researchers have developed the equation to estimate the water content as well as the dielectric permittivity in respect of an organic soil such as peat (35). Estimation of the SWC from the previous model can be categorized into one parameter or two parameters. One parameter is defined as where it only involves the dielectric permittivity and water content, whereas two parameters include other parameters, such as the bulk density or porosity. For example, using the Topp's equation, the model is:

$\varepsilon=3.03+9.3 \theta+146 \theta^{2}-76.7 \theta^{a}$

where $\varepsilon$ is the dielectric permittivity and $\theta$ is the water content of the soil. This measurement uses the TDR at a frequency of 1 to 1000 $\mathrm{MHz}$ for several mineral soils. Topp used a polynomial fitting to obtain the $\varepsilon-\theta$ relationship model.(36) produced another equation for determination of the SWC which is still used by researchers. The equation is as follows:

$$
\begin{aligned}
& \theta=-5.3 \times 10^{-2}+2.92 \times 10^{-2} \varepsilon-5.5 \times 10^{-4} \varepsilon^{2}+4.3 \times \\
& 10^{-6} \varepsilon^{3}
\end{aligned}
$$

Other researchers have formed various equations for estimating the SWC of organic soils. Over the years, researchers have focused on organic soil as it is different to other soils. Hence, the model is different. For example, Topp's equation is not suitable for organic soil as it tends to deviate from it (37), as was also reported by(38). The difference between the dielectric permittivity and the water content in organic soil compared to the mineral soil is due to the difference in the bulk density and surface area(39). (35) used a miniprobe and TDR to form equations for mineral soil and organic soil. The equations are as follows:

Mineral Soil:

$$
0.0000361 \varepsilon^{a} \quad \theta=-0.0728+0.0448 \varepsilon-0.00195 \varepsilon^{2}+
$$

Organic Soil:

$$
\theta=-0.0233+0.0285 \varepsilon-0.000431 \varepsilon^{2}+0.00000304 \varepsilon^{3}
$$

(35) also found that the error estimation for mineral soil is $0.015 \mathrm{~cm}^{3} \mathrm{~cm}^{-3}$, while for an organic soil it is $0.035 \mathrm{~m}^{3} \mathrm{~m}^{-3}$. Other researchers $(40,41)$ also provide an SWC model. (40) used a mixing model equation and TDR measurements to form an equation. The equation is as follows:

$\theta=0.1181 \sqrt{\varepsilon}-0.1841$ 
(41) chose a different approach to(40), and formed a model for organic soil. These researchers used 505 measurements from an organic forest using TDR measurements. The equation is as follows:

$\theta=0.136 \sqrt{\varepsilon}-0.119$

(42) derived a third order polynomial empirical relationship, w, which defines the volumetric water content (VWC) and dielectric permittivity(43).

$$
\begin{aligned}
& \theta=2.3 \times 10^{-4} \varepsilon^{3}-6.28 \times 10^{-3} \varepsilon^{2}+7.5 \times 10^{-2} \varepsilon-1.51 \times \\
& 10^{-1}
\end{aligned}
$$

Other researchers developed an equation with two parameters using either bulk density or porosity. For example, (44) formed equations using the porosity parameters.

$$
\begin{aligned}
& \varepsilon=\theta\left(\varepsilon_{\mathrm{i}}+\left(\varepsilon_{W}-\varepsilon_{\mathrm{i}}\right) \frac{\theta}{\theta_{\mathrm{r}}} \gamma\right)+(\eta-\theta) \varepsilon_{0}+(1-\eta) \varepsilon_{Y} \\
& \varepsilon=\theta_{\mathrm{t}}\left(\varepsilon_{\mathrm{i}}+\left(\varepsilon_{W}-\varepsilon_{\mathrm{i}}\right) \gamma\right)+\left(\theta-\theta_{\mathrm{t}}\right) \varepsilon_{\mathrm{W}}+(\eta-\theta) \varepsilon_{\mathrm{a}}+(1-\eta) \varepsilon
\end{aligned}
$$

where $\varepsilon_{i}$ is the permittivity for ice (3.2), $\varepsilon_{w}$ is the permittivity for water (80), and $\varepsilon_{F}$ for rock (0.5). The first equation is applied where $\theta \leq \theta_{t}$, while the second equation is applied where $\theta>\theta_{t}$. From the above equations for SWC, it can be concluded that the dielectric permittivity is a vital component in the SWC model.

In this paper, the petrophysical relationship, Roth's equation and Schaap's equation were chosen to retrieve the value of the SWC. These empirical equations were chosen based on the suitability of the soil. In addition, these relationships provide reliable estimates of the SWC which does not need the use of detailed of soil textural information such as porosity, bulk density and others. The use of these relationships indicate the value of water content for a range of soil moisture and textural properties. Other researchers (45) used GPR to determine the velocity of the EM waves through the subsurface. By using the velocity from the electromagnetic waves, the dielectric constant can be calculated. The dielectric constant is then derived to determine the water content using an empirical equation, such as Topp's equation, or multiple formulae to describe the relationships between the dielectric permittivity and the hydrologic parameter. Figure 4. depicts the flowchart of the study in which all the related procedures and phases are indicated. The figure provides an overview of the phase on the data collection process. As evidenced in the flowchart, the study is designed and conducted in five phases: Field survey measurements (Data collection), basic processing, radargram standardization, geometric matching/checking, and the petrophysical relationships. Data collection involves GPR scanning of the peat soil. The acquired radargram images were processed based on certain techniques, such as subtract mean (dewow), static correction, gain functions, and background removal to remove the unnecessary signals. The parameters involved in the GPR scanning were time/depth conversion, and the velocity and dielectric permittivity of the soil. Then, using the appropriate petrophysical relationship, the value of the SWC was retrieved. A few petrophysical relationships have been developed by previous researchers for all types of soil to estimate the value of the water content. However, only a few empirical relationships exist that are suitable for organic soil, especially for peat soil. Hence, in this study, Roth's equation and Schaap's equation were chosen for converting the dielectric permittivity to the SWC.

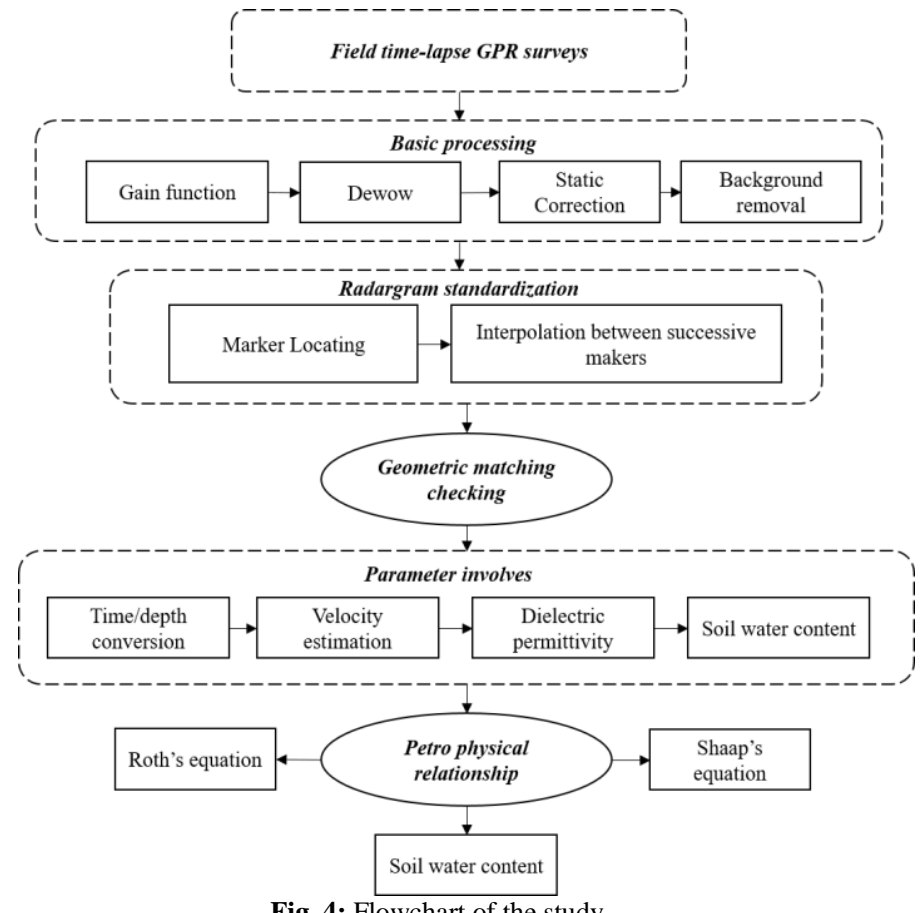

Fig. 4: Flowchart of the study

\section{Results}

Using an appropriate equation, the GPR data were analyzed using two equations (i.e., Roth's equation and Schaap's equation) to estimate the water content of the peat soil as well as the dielectric permittivity. The number of output files selected was 512 samples per scan. To obtain the best results, when processing the data, any kind of interference (noise) needs to be removed. The subtract mean filter, gain functions, dewow, and background removal were applied to remove the noise. After filtering and processing, the color of the radargrams was transformed making the layers more visible. Figure 5 depicts the interpretation of the processed radargrams using $250 \mathrm{MHz}$ and $700 \mathrm{MHz}$ antenna frequencies indicating the potential moisture content. The diagrams show a clear difference between the two types of data $(250 \mathrm{MHz}$ and $700 \mathrm{MHz})$. The depth of penetration of the $250 \mathrm{MHz}$ antenna of GPR was deeper even though the resolution was lower than that of the $700 \mathrm{MHz}$ antenna. Consequently, in the present case in peat soil area, the results between $250 \mathrm{MHz}$ and $700 \mathrm{MHz}$ showed clearly different, where the lower frequency $(250 \mathrm{MHz})$ shows deeper penetration which the potential moisture content of the soil can be identified in deeper layer.

Appropriate and suitable petrophysical relationship is needed to convert the dielectric permittivity information into the volumetric water content. For this study, Roth's equation and Schaap's equation were used to determine the value of the volumetric water content for $250 \mathrm{MHz}$ and $700 \mathrm{MHz}$. The GPR provides information about the velocity that can be used to convert the value to dielectric permittivity. The velocity was recorded as $\mathrm{V}\left(\mathrm{mns}^{-1}\right)$, which was extracted from the radargram information and used together with the t-values to compute the depth. For each hyperbola, the velocity was converted to dielectric permittivity, and then converted to water content using the equations (Roth's equation and Schaap's equation). Fig 4 shows the validation graph of the water content between $250 \mathrm{MHz}$ and $700 \mathrm{MHz}$; using both equations the correlation coefficient for $250 \mathrm{MHz}$ (left) is $0.8869 \mathrm{~m}^{3} \mathrm{~m}^{-3}$ and for $700 \mathrm{MHz}$ (right) it is $0.4031 \mathrm{~m}^{3} \mathrm{~m}^{-3}$. The results show slightly greater differences between the correlations. The antenna frequencies determine the depth of penetration and resolution of the soil with a consistent dielectric permittivity. As mentioned by Hiroko (46), a higher frequency leads to a higher resolution but lower depth penetration than a lower frequency. Fig 4. Shows the curves for Roth's equation and Schaap's equation, both of which use one parameter. Equations with one parameter only use the dielectric permittivity parameter to estimate the water content. 

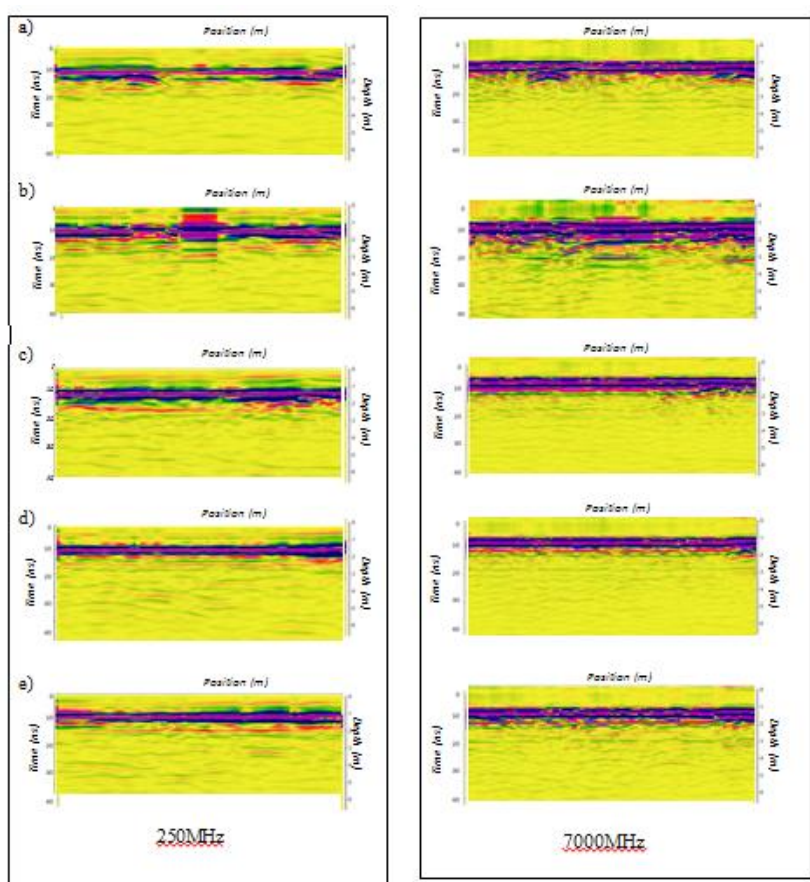

Fig. 5: Processed Radargrams profile for $250 \mathrm{MHz}$ and $700 \mathrm{MHz}$

Based on the graph, a comparison between Roth's equation and Schaap's equation was made to estimate the SWC of the peat soil. For the $250 \mathrm{MHz}$ frequency, the correlation is slightly greater between the equations; Schaap's equation shows $0.9928 \mathrm{~m}^{3} \mathrm{~m}^{-3}$ and Roth's equation shows $0.8313 \mathrm{~m}^{3} \mathrm{~m}^{-3}$. Meanwhile, for the $700 \mathrm{MHz}$ frequency, the correlation coefficient for Schaap's equation is $0.9529 \mathrm{~m}^{3} \mathrm{~m}^{-3}$, and, for Roth's equation, it is $0.5529 \mathrm{~m}^{3} \mathrm{~m}^{-3}$. Schaap's equation shows a higher correlation for both frequencies compared to Roth's equation. The difference between the values of the correlation for these equations could be due to the petrophysical experiment to develop these equations. As mentioned by (47), Schaap's equation was based on 505 measurements from an organic forest sample experiment using Time Domain Reflectometry (TDR), while seven organic soils were used to develop Roth's equation (47). Even though it is not certain whether Roth's or Schaap's equation is more reliable at high or low water content, the lack of correlation between these equations at high/low water content should be treated with caution.
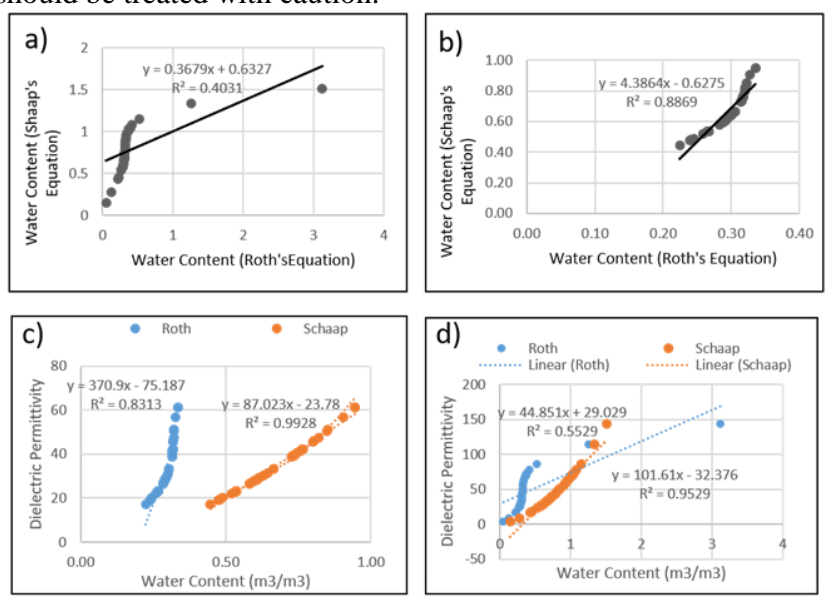

Fig. 6: Validation graph of the water content (Roth's equation) versus the water content (Schaap's equation) for $700 \mathrm{MHz}$ (a) and $250 \mathrm{MHz}$ (b) and the validation graph of the water content versus the dielectric permittivity in terms of the performance of Roth's equation and Schaap's equation between $250 \mathrm{MHz}$ (c) and $700 \mathrm{MHz}(\mathrm{d})$

\section{Conclusion}

In this research, the performance of different frequencies was studied and applied to determine the SWC of peat soil. The study was carried out on peat soil using the GPR IDS Detector Duo to retrieve the velocity from the radargram profiles. The velocity was then converted to dielectric permittivity using an an appropriate equation. Roth and Schaap's equations were chosen to estimate the water content of peat soil for $250 \mathrm{MHz}$ and $700 \mathrm{MHz}$. The correlation for $250 \mathrm{MHz}$ between Roth's equation and Schaap's equation demonstrates that GPR provides deeper penetration compared to higher antenna frequencies $(700 \mathrm{MHz})$ but is lower in resolution. Meanwhile, the performance of both equations was tested to obtain the trends of the equation for estimating the SWC estimation. Schaap's equation shows a better correlation compared to Roth's equation for peat soil.

\section{Acknowledgement}

The authors would like to express their appreciation for the support of the Ministry of Education (MOE) and Universiti Teknologi Malaysia (UTM) sponsorship through the research university grant (GUP) for the Project No. 12H96.

\section{References}

[1] Tang W. Monitoring Soil Moisture and Freeze / Thaw State Using C-band Imaging Radar. 2015.

[2] Aguilera H, Moreno L, Wesseling JG, Jimenez-Hernandez ME, Castano S. Soil moisture prediction to support management in semiarid wetlands during drying episodes. Catena. 2016;147:709-24.

[3] Altendorf CT, Elliott RL, Stevens EW, Stone ML. Development and validation of a neural network model for soil water content prediction with comparison to regression techniques. Transactions of the ASAE. 1999;42(3):691-.

[4] Noborio K. Measurement of soil water content and electrical conductivity by time domain reflectometry: A review. Computers and Electronics in Agriculture. 2001;31(3):213-37.

[5] Souza CF, Matsura EE. Multi-wire TDR probe evaluation to monitor soil water content. Revista Brasileira de Engenharia Agrícola e Ambiental. 2002;6(1):63-8.

[6] Lihua Z, Minzan L, Jianying S, Xijie Z, Peng Z. ' r ; Jr ii. 2005;5909:1-8.

[7] Imhoff PT, Reinhart DR, Englund M, Gu??rin R, Gawande N, Han $\mathrm{B}$, et al. Review of state of the art methods for measuring water in landfills. Waste Management. 2007;27(6):729-45.

[8] Anderson K, Croft H. Remote sensing of soil surface properties. Progress in Physical Geography. 2009;33(4):457-73.

[9] Calamita G, Brocca L, Perrone a, Piscitelli S, Lapenna V, Melone F, et al. Electrical resistivity and TDR methods for soil moisture estimation in central Italy test-sites. Journal of Hydrology. 2012;454 455:101-12.

[10] Robinson DA, Campbell CS, Hopmans JW, Hornbuckle BK, Jones SB, Knight R, et al. Soil moisture measurement for ecological and hydrological watershed-scale observatories: A review. Vadose Zone Journal. 2008;7(1):358-89.

[11] Huisman Ja, Hubbard SS, Redman JD, Annan aP. Measuring Soil Water Content with Ground Penetrating Radar A Review. Vadose Zone Journal. 2003;2:476-91.

[12] Galagedara LW, Parkin GW, Redman JD. An analysis of the groundpenetrating radar direct ground wave method for soil water content measurement. Hydrological Processes. 2003;17(18):3615-28.

[13] Doolittle Ja, Jenkinson B, Hopkins D, Ulmer M, Tuttle W. Hydropedological investigations with ground-penetrating radar (GPR): Estimating water-table depths and local ground-water flow pattern in areas of coarse-textured soils. Geoderma. 2006;131(34):317-29.

[14] Weihermüller L, Huisman JA, Lambot S, Herbst M, Vereecken H. Mapping the spatial variation of soil water content at the field scale with different ground penetrating radar techniques. Journal of Hydrology. 2007;340(3):205-16.

[15] Doolittle JA, Sudduth KA, Kitchen NR, Indorante SJ. Estimating depths to claypans using electromagnetic induction methods. Journal of Soil and Water Conservation. 1994;49(6):572-5. 
[16] Sheets KR, Hendrickx JMH. Noninvasive soil water content measurement using electromagnetic induction. Water resources research. 1995;31(10):2401-9.

[17] Sudduth Ka, Drummond ST, Kitchen NR. Accuracy issues in electromagnetic induction sensing of soil electrical conductivity for precision agriculture. Computers and Electronics in Agriculture. 2001;31(3):239-64.

[18] Dabas M, Tabbagh J, Boisgontier D, editors. Multi-depth continuous electrical profiling (MuCep) for characterization of in-field variability2001.

[19] Lund ED, Christy CD, Drummond PE. Practical Applications of Soil Electrical Conductivity Mapping. the 2nd European Conference on Precision Agriculture. 1999(July):1-9.

[20] Pallavi B, Saito H, Kato M. Application of GPR ground wave for mapping of spatiotemporal variations in the surface moisture content at a natural field site. 19th World Congress of Soil Science, Soil Solutions for a Changing World. 2010(August):13-6.

[21] Mai TC, Razafindratsima S, Sbartaï ZM, Demontoux F, Bos F. Nondestructive evaluation of moisture content of wood material at GPR frequency. Construction and Building Materials. 2015;77:213-7.

[22] Li M, Birken R, Sun NX, Wang ML. Compact Slot Antenna With Low Dispersion for Ground Penetrating Radar Application. IEEE Antennas and Wireless Propagation Letters. 2016;15:638-41.

[23] Rezanezhad F, Price JS, Quinton WL, Lennartz B, Milojevic T, Van Cappellen P. Structure of peat soils and implications for water storage, flow and solute transport: A review update for geochemists. Chemical Geology. 2016;429:75-84

[24] Senin SF, Hamid R. Ground penetrating radar wave attenuation models for estimation of moisture and chloride content in concrete slab. Construction and Building Materials. 2016;106:659-69.

[25] Fu L, Liu S, Liu L, Lei L. Development of an Airborne Ground Penetrating Radar System - Antenna Design, Laboratory Experiment, and Numerical Simulation. 2014;7(3):761-6.

[26] Harari Z. Ground-penetrating radar (GPR) for imaging stratigraphic features and groundwater in sand dunes. Journal of Applied Geophysics. 1996;36(1):43-52.

[27] Topp GC, Davis JL, Annan AP. Electromagnetic determination of soil water content and electrical conductivity measurement using time domain reflectometry. Water Resources Research. 1980;16(3):574-82.

[28] Van Genuchten MT. A closed-form equation for predicting the hydraulic conductivity of unsaturated soils. Soil science society of America journal. 1980;44(5):892-8

[29] Dobriyal P, Qureshi A, Badola R, Hussain SA. A review of the methods available for estimating soil moisture and its implications for water resource management. Journal of Hydrology. 2012;458 459:110-7.

[30] O'Neal DP, Hirsch LR, Halas NJ, Payne JD, West JL. Photo-thermal tumor ablation in mice using near infrared-absorbing nanoparticles. Cancer letters. 2004;209(2):171-6.

[31] Parsekian AD, Slater L, Ntarlagiannis D, Nolan J, Sebesteyen SD, Kolka RK, et al. Uncertainty in Peat Volume and Soil Carbon Estimated Using Ground-Penetrating Radar and Probing. Soil Science Society of America Journal. 2012;76(5):1911-

[32] Annan aP. Ground Penetrating Radar Principles, Procedure \& Applications. Ground Penetrating Radar Theory and Applications. 2009; Ground Pen:iv-iv.

[33] Davis JL, Annan AP. Ground-penetrating radar for high-resolution mapping of soil and rock stratigraphy. Geophysical prospecting. 1989;37(5):531-51.

[34] Grote K. Field-scale estimation of volumetric water content using ground-penetrating radar ground wave techniques. Water Resources Research. 2003;39(11):1-14

[35] Roth CH, Malicki MA, Plagge R. Empirical evaluation of the relationship between soil dielectric constant and volumetric water content as the basis for calibrating soil moisture measurements by TDR. Journal of Soil Science. 1992;43(1):1-13.

[36] Topp GC, Davis JL. Measurement of soil water content using timedomain reflectrometry (TDR): a field evaluation. Soil Science Society of America Journal. 1985;49(1):19-24.

[37] Noraini R, Seca G, Johan I, Mohd IJ. Comparative study of water quality at different peat swamp forest of Batang Igan, Sibu Sarawak. American Journal of Environmental Sciences. 2010;6(5):416-21.

[38] Comas X, Slater L, Reeve A. Spatial variability in biogenic gas accumulations in peat soils is revealed by ground penetrating radar (GPR). Geophysical Research Letters. 2005;32(8).
[39] Pumpanen J, Ilvesniemi H. Calibration of time domain reflectometry for forest soil humus layers. 2005.

[40] Ferre PA, Knight JH, Rudolph DL, Kachanoski RG. The sample areas of conventional and alternative time domain reflectometry probes. Water Resources Research. 1998;34(11):2971-9.

[41] Schaap MG, Bouten W, Verstraten JM. Forest floor water content dynamics in a Douglas fir stand. Journal of Hydrology. 1997;201(14):367-83.

[42] Lambot S, Weihermüller L, Huisman JA, Vereecken H, Vanclooster M, Slob EC. Analysis of air-launched ground-penetrating radar techniques to measure the soil surface water content. Water resources research. 2006;42(11)

[43] Jonard F, Weihermüller L, Vereecken H, Lambot S. Accounting for soil surface roughness in the inversion of ultrawideband off-ground GPR signal for soil moisture retrieval. Geophysics. 2012;77(1):H1 H7.

[44] Wang JR, Schmugge TJ. An empirical model for the complex dielectric permittivity of soils as a function of water content. IEEE Transactions on Geoscience and Remote Sensing. 1980;GE18(4):288-95.

[45] Zehe E, Graeff T, Morgner M, Bauer a, Bronstert a. Plot and field scale soil moisture dynamics and subsurface wetness control on runoff generation in a headwater in the Ore Mountains. Hydrology and Earth System Sciences. 2010;14(6):873-89.

[46] Okazaki H, Nakazato H, Kwak Y. Application of high-frequency ground penetrating radar to the reconstruction of 3D sedimentary architecture in a flume model of a fluvial system. Sedimentary Geology. 2013;293:21-9.

[47] Mukhlisin M, Saputra A. Performance evaluation of volumetric water content and relative permittivity models. The Scientific World Journal. 2013;2013. 